\title{
AVALIAÇÃO DO COMPONENTE ARBÓREO E FORRAGEIRO DE SISTEMAS SILVIPASTORIS NA MESORREGIÃO DOS "CAMPOS DAS VERTENTES" DE MINAS GERAIS ${ }^{1}$
}

Ana Carolina Machado Pereira ${ }^{2}$, João Carlos Carvalho de Almeida ${ }^{3}$, Thais Glaucia Bueno Moreira ${ }^{4}$, Pablo Gilliard Zanella ${ }^{5}$, Carlos Augusto Brandão de Carvalho ${ }^{3}$, Leonardo Fiusa de Morais ${ }^{4}$, Felipe Almeida Soares $^{6}$, Marina Aparecida Lima ${ }^{7}$

\begin{abstract}
RESUMO - Objetivou-se com esse estudo avaliar o potencial produtivo do pasto de Urochloa decumbens sob três arranjos silvipastoris mais o tratamento controle (monocultivo) além das características dendrométricas de Eucaliptus urophylla nos espaçamentos 3x2, 6x4 e 10x4 m dos 48 meses aos 66 meses pós-plantio do eucalipto. O delineamento experimental utilizado foi em blocos completos casualizados, com quatro blocos e duas repetições por bloco. Para avaliar a forrageira e o eucalipto, foram utilizados os arranjos em parcelas subdivididas. Para avaliar as distâncias da linha de plantio do eucalipto de cada espaçamento, foi utilizado o arranjo em parcela subsubdividida. O acúmulo de forragem, taxa de acúmulo de forragem, altura e teor de matéria seca da forrageira foram maiores no monocultivo. O teor de proteína bruta foi maior no espaçamento 6x4 m. Os menores teores de fibra em detergente neutro foram encontrados nos tratamentos sombreados. A altura do eucalipto teve influência somente de idade. O diâmetro a altura do peito, diâmetro de copa foram maiores nos espaçamentos 6x4 e 10x4 m. A relação altura: diâmetro a altura do peito foi maior no espaçamento $3 \times 2 \mathrm{~m}$. O volume/planta foi maior no espaçamento $6 \times 4$ e 10x4 m, respectivamente. O volume/ha e incremento médio anual foram maiores no espaçamento $3 \times 2 \mathrm{~m}$. O espaçamento $6 \times 4 \mathrm{~m}$ até os 5,5 anos de avaliação é o mais indicado para produção e qualidade de pasto e produção de madeira.
\end{abstract}

Palavras chave: Eucalyptus urophylla, sistemas agroflorestais, Urochloa decumbens.

\section{EVALUATION OF THE TREE AND FORAGE COMPONENT OF SILVOPASTORAL SYSTEMS IN THE MIDDLE REGION OF THE "CAMPOS VERTENTES" OF MINAS GERAIS}

\begin{abstract}
The objective of this study was to evaluate the productive potential of pasture Urochloa decumbens under three silvipastoral arrangements over the control treatment (monoculture pasture) beyond dendrometric characteristics of Eucalyptus urophylla in spacing 3x2, 6x4 and $10 x 4 \mathrm{~m}$ from 48 to 66 months post eucalyptus plantation. The experimental design was a randomized complete block with four blocks and two replicates per block. To evaluate the forage and eucalyptus arrangement it was used split plots. To evaluate the distances of eucalyptus planting line on each space of each arrangement it was used a split plot. The accumulation offorage, rate of forage accumulation and height of the forage were higher in monoculture. The crude protein content was higher in $6 \times 4 \mathrm{~m}$ spacing. The lowest neutral fiber detergent percentages were found in the shaded treatments. The height of eucalyptus has influenced just by age. The diameter at breast height and diameter
\end{abstract}

${ }^{1}$ Parte da dissertação do primeiro autor; Projeto financiado pela UFRRJ.

${ }^{2}$ Discente Programa de Pós-Graduação em Zootecnia/Universidade Federal Rural do Rio de Janeiro. E-mail: carolinamachadozootecnista@gmail.com

${ }^{3}$ Zootecnista, D.Sc., Professor Adjunto do Departamento de Zootecnia da Universidade Federal Rural do Rio de Janeiro - UFRRJ.

${ }^{4}$ Discente Programa de Pós-Graduação em Zootecnia/Universidade Federal Rural do Rio de Janeiro.

${ }^{5}$ Discente Programa de Pós-Graduação em Zootecnia/Universidade Estadual de Santa Catarina.

${ }^{6}$ Discente de Zootecnia/Universidade Federal Rural do Rio de Janeiro.

${ }^{7}$ Discente Programa de Pós-Graduação em Zootecnia/Universidade Federal de Viçosa.

Revista Brasileira de Agropecuária Sustentável (RBAS), v.5, n.1., p.66-77, Julho, 2015 
of cup were higher in spacing $6 \times 4$ and $10 \times 4 \mathrm{~m}$. The ratio height: diameter at breast height was higher in $3 \times 2 \mathrm{~m}$ spacing. The vol/plant was higher in spacing $6 \times 4$ and $10 \times 4 \mathrm{~m}$, respectively. The vol/ha and increase annual average were higher in $3 \times 2 \mathrm{~m}$ spacing. The spacing of $6 \times 4 \mathrm{~m}$ up to 5.5 years of evaluation is the most suitable for the production and quality of pasture and timber production.

Keywords: agroforestry systems, Eucalyptus urophylla, Urochloa decumbens.

\section{INTRODUÇÃO}

A população mundial, até o ano de 2050, passará de 7 para 9 bilhões de pessoas e, consequentemente, a produção de alimentos deverá aumentar em torno de 70\% ONU, 2013). Em contrapartida, o Brasil apresenta um grande território, o que permite que parte dos alimentos seja produzida em solos brasileiro, para atender a demanda por esses produtos. No entanto, a produção animal, particularmente a produção de ruminantes à pasto, é prejudicada devido ao estado em que se encontram as pastagens brasileiras. Dos 180 milhões de hectares de pasto (nativo e cultivado), $85 \%$ encontram-se em diversos níveis do processo de degradação (IBGE, 2006), e desta maneira, não correspondem à produtividade esperada e geram prejuízos ambientais e econômicos.

Para amenizar a degradação das pastagens e diminuir a abertura de novas áreas para a produção animal, técnicas que visam uma produção sustentável vêm sendo estudadas e ganhando força mundialmente, pois direciona a utilização de sistemas que são capazes de suprir as necessidades atuais, sem comprometimento dos recursos naturais para as gerações futuras. Dentre estas técnicas, os sistemas agroflorestais (SAFs) permitem otimizar a produção por unidade de área, seguindo sempre os preceitos de conservação dos recursos naturais , através dos aspectos de dinamismo e interação entre os componentes do sistema.

Uma das alternativas para esses sistemas é o uso de eucalipto como componente arbóreo, sendo a determinação de arranjos espaciais de plantio, de forma a otimizar a produção de madeira e forragem, um desafio para o seu estabelecimento (Macedo et al., 2010). O Eucalyptus possui uma grande variedade de espécies com alta plasticidade ecológica, com potencial de estabelecimento, produção e adaptação a diferentes condições dafoclimáticas e, por isso, é a cultura silvícola mais pesquisada e sua exploração é crescente (Macedo et al., 2010), devido a demanda por madeira em diversos setores da indústria.
O objetivo do estudo foi avaliar as características produtivas, estruturais e composição bromatológica do pasto de Urochloa decumbens (capim-braquiária) em monocultivo e em três sistemas silvipastoris com eucalipto e as características dendrométricas do Eucalyptus urophylla nos espaçamentos $3 \times 2,6 \times 4$ e $10 \times 4 \mathrm{~m}$.

\section{MATERIAL E MÉTODOS}

O estudo foi realizado na Fazenda Registro, localizada no município de Barbacena-MG, situada à latitude de $21^{\circ} 15^{\prime} 18^{\prime \prime} \mathrm{S}$, longitude de $43^{\circ} 44^{\prime} 01^{\prime \prime}$ W e a $1.092 \mathrm{~m}$ de altitude. O clima é do tipo Cwb (Classificação de Köppen), tropical de altitude, com invernos frios e verões brandos, por ser uma região de relevo serrano. As médias de temperatura máxima e mínima são $24,4^{\circ} \mathrm{C}$ e $13,8^{\circ} \mathrm{C}$, respectivamente. $\mathrm{O}$ índice pluviométrico é de aproximadamente $1.436 \mathrm{~mm}$ durante o ano, distribuído nos meses de outubro a abril (INMET, 2014).

Foi realizada análise de solo da área experimental, onde as amostras foram coletadas, nas unidades experimentais em cada unidade de amostragem, nas profundidades de $0-20 \mathrm{~cm}$ e $20-40 \mathrm{~cm}$, que revelou no espaçamento $3 \times 2 \mathrm{~m}$ valores de 0,78 e $0,41 \mathrm{de} \mathrm{Ca} \mathrm{cmol}_{\mathrm{c}}$ I $\mathrm{dm}_{3}, 0,37$ e $0,20 \mathrm{cmol}_{\mathrm{c}} / \mathrm{dm}_{3}$, de $\mathrm{Mg}, 9,5$ e 2,4 mg/L de P, 12 e $9 \%$ de V, 3,6 e 2,5\% de carbono orgânico, respectivamente. No espaçamento $6 \mathrm{x} 4 \mathrm{~m}$ os valores foram 1,1 e 0,76 de $\mathrm{Ca} \mathrm{cmol} / \mathrm{dm}_{3}, 0,52$ e $0,23 \mathrm{cmol} / \mathrm{dm}_{3}$, de $\mathrm{Mg}, 7,2$ e 3,3 mg/L de P, 19 e $15 \%$ de V, 2,49 e 1,86 $\%$ de carbono orgânico, respectivamente. No espaçamento $10 \times 4 \mathrm{~m}$ os valores foram 1,5 e 0,71 de $\mathrm{Ca} \mathrm{cmol} / \mathrm{dm}_{3}, 0,57$ e 0,22 $\mathrm{cmol}_{\mathrm{c}} / \mathrm{dm}_{3}$, de $\mathrm{Mg}, 6,6,2$ e 3,2 $\mathrm{mg} / \mathrm{L}$ de $\mathrm{P}, 18$ e $13 \%$ de V, 2,55 e 3,52\% de carbono orgânico, respectivamente. No monocultivo os valores foram 2,3 e 1,0 de $\mathrm{Ca} \mathrm{cmol} / \mathrm{dm}_{3}, 1,0$ e 0,20 $\mathrm{cmol}_{\mathrm{c}} / \mathrm{dm}_{3}$, de $\mathrm{Mg}, 5,0$ e 2,0 mg/L de P, 27 e $16 \%$ de V, 3,3 e 1,8 $\%$ de carbono orgânico, respectivamente.

Foi realizada a prática de calagem aplicando-se uma tonelada de calcário dolomítico por hectare, no ano de 2007, conforme os resultados da análise química e a exigência do capim-braquiária, segundo Cantarutti 
et al. (1999). Em seguida realizou-se a fosfatagem utilizando $100 \mathrm{~kg} / \mathrm{ha}$ de $\mathrm{P}_{2} \mathrm{O}_{5}$, na forma de superfosfato simples, aplicados de uma só vez em cobertura. Para adubação de manutenção, foram utilizado $30 \mathrm{~kg} / \mathrm{ha}$ de $\mathrm{N}$ na forma de ureia e $25 \mathrm{~kg} / \mathrm{ha}$ de $\mathrm{K}_{2} \mathrm{O}$ na forma de cloreto de potássio, aplicadas em cobertura, após cada corte realizado durante as estações das águas.

O Eucalyptus urophylla foi plantado no sentido leste-oeste nos espaçamentos $3 \times 2 \mathrm{~m}, 6 \times 4 \mathrm{~m}$ e $10 \times 4 \mathrm{~m}$ em janeiro de 2008, em uma pastagem de Urochloa decumbens (capim-braquiária) de 2,27 ha, formada há 15 anos.

As unidades experimentais, onde foram aplicadas aos tratamentos monocultivo,

$3 \times 2,6 \times 4$ e 10x4 m, têm dimensões de 28, 6, 12 e $20 \mathrm{~m}^{2}$, respectivamente. Nos espaçamentos de plantio do eucalipto foram alocadas quatro unidades de amostragens por unidade experimental, em diferentes distâncias das linhas de plantio do eucalipto, sendo uma a 0\% (linha do eucalipto) e as demais a 33, 66 e a $99 \%$ em relação ao meio da entrelinha do eucalipto.

As avaliações foram feitas no verão $1(06 / 01 / 12$ e 01/03/12), primavera (13/12/12), verão 2 (07/03/13) e outono (23/05/13). Em 15 de outubro de 2012 foi feito um corte de uniformização do pasto de capim-braquiária.

Para avaliar as árvores de eucalipto foram utilizadas 255 árvores do espaçamento $3 \times 2 \mathrm{~m}, 129$ do $6 \times 4 \mathrm{~m} \mathrm{e}$ 151 do $10 \times 4 \mathrm{~m}$. E as medidas foram coletadas em janeiro e julho dos anos de 2012 e 2013.

Os tratamentos consistiram nos espaçamentos de plantio do eucalipto ( $3 \times 2 \mathrm{~m}$, com 1.666 árvores/ha, $6 \times 4$ $\mathrm{m}$, com 416 árvores/ha e 10x4 m, com 250 árvores/ha) e ausência de árvores (monocultivo). Eles foram organizados sob um delineamento experimental em blocos completos casualizados, com quatro blocos, e duas repetições por bloco.

Para avaliar o capim-braquiária no monocultivo e os espaçamentos nas diferentes estações, foi utilizado o arranjo em parcelas subdivididas. Para avaliar o efeito das diferentes distâncias da linha de plantio do eucalipto $(0,33,66$ e $99 \%)$ nos espaçamentos nas diferentes estações, foi utilizado o arranjo em parcelas subsubdivididas. A avaliação dos espaçamentos entre as árvores e as idades de avaliação do eucalipto pósplantio (48, 54, 60 e 66 meses), foi organizada num arranjo em parcelas subdivididas.
O critério de desfolhação foi a altura da forrageira no monocultivo ao atingir $30 \mathrm{~cm}$, a qual foi obtida por meio do método da altura "não comprimida". Posteriormente, foram realizadas medições da altura com uma régua graduada em milímetros (Da Silva \& Cunha, 2003), em uma área útil de 0,5x 0,5 m (moldura metálica), em cada unidade de amostragem.

O acúmulo de forragem foi obtido utilizando os valores de massa de forragem estimados na moldura metálica, onde a forragem foi cortada a $15 \mathrm{~cm}$ do nível do solo, nas distâncias da linha do eucalipto de 0,33 , 66 e $99 \%$, pesada e encaminhada para estufa de circulação de ar forçada a $55^{\circ} \mathrm{C}$ por 72 horas, para obtenção da massa seca (MS); a taxa de acúmulo de forragem foi obtida pela divisão dos valores de acúmulo de forragem a cada avaliação, pelos respectivos intervalos de corte em dias; a relação lâmina foliar:colmo+bainha foi obtida pela retirada de 15 perfilhos rentes ao solo da unidade experimental, nas linhas de distâncias do eucalipto, os quais foram separados em lâmina foliar e colmo+bainha, colocados separadamente em sacos de papel, pesados e então encaminhados para estufa de circulação de ar forçada à $55^{\circ} \mathrm{C}$ por 72 horas para obtenção da massa seca. A relação foi calculada dividindo a massa seca de lâmina foliar pela massa seca de colmo+bainha.

A composição bromatológica do capim-braquiária cortada a $15 \mathrm{~cm}$ do nível do solo foi obtida através das análises de porcentagem de teor de matéria seca (MS), de proteína bruta (PB), de fibra em detergente neutro (FDN) e de matéria mineral (MM) como descrito por Silva \& Queiroz (2002). As análises bromatológicas foram realizadas no Laboratório de Bromatologia do Departamento de Nutrição Animal e Pastagem da Universidade Federal Rural do Rio de Janeiro.

As avaliações do eucalipto foram: altura total das plantas em metros, medida do nível do solo até o topo das árvores, determinada com o auxílio de hipsômetro; o diâmetro a altura do peito (DAP), obtido através da circunferência à altura do peito (CAP) $(1,30 \mathrm{~m}$ acima do nível do solo) de todas as plantas dentro da área útil de cada unidade experimental, com o auxílio de uma fita métrica com precisão em centímetros e calculado através da fórmula DAP $=\mathrm{CAP} /$; ; relação altura: $\mathrm{DAP}$ foi obtida através das médias dos valores de altura do eucalipto dividido pelas médias dos valores de DAP; o diâmetro da copa, obtido através da média dos diâmetros de copa no sentido leste-oeste e norte-sul, utilizando- 
se de uma fita métrica com precisão em metros; o volume por planta dos indivíduos da área útil de unidade experimental, obtido por meio da expressão a seguir:

$V=\frac{\left(D A P^{2} \times H \times \pi\right) \times f}{40000}(\mathrm{f}=0,42$ adotado pela C.M.M. para os trabalhos de inventário); volume por hectare, obtido pela multiplicação do volume por planta pelo número de árvores por hectare, para cada espaçamento avaliado; o incremento médio anual do volume por hectare $\left(\mathrm{m}^{3} / \mathrm{ha}\right)$, calculado pela divisão do volume total por hectare pela idade atual do povoamento florestal, em anos, por ocasião de cada avaliação. Todas as avaliações foram realizadas aos 48, 54, 60 e 66 meses de plantio do eucalipto.

As análises de variância foram analisadas por meio do procedimento MIXED do pacote estatístico SAS ${ }^{\circledR}$ (Statistical Analysis System), versão 9.0 para Windows. A escolha das matrizes de variância e de covariância foi feita utilizando-se o Critério de Informação de Akaike (Wolfinger, 1993). Para comparar o efeito das distâncias da linha de plantio do eucalipto no capim-braquiária, e as idades de plantio do eucalipto utilizou o procedimento PROC REG do pacote estatístico SAS. Os resultados foram submetidos à análise de variância (ANOVA) com aplicação do teste F. As médias entre tratamentos foram estimadas utilizando-se o "LSMEANS", e a comparação entre elas foi realizada por meio da probabilidade da diferença ("DIFF"), a 5\% de probabilidade.

\section{RESULTADOS E DISCUSSÃO}

O acúmulo de forragem do capim-braquiária no monocultivo apresentou maiores valores em relação aos demais tratamentos estudados (Tabela 1).

O espaçamento $10 \times 4 \mathrm{~m}$ foi o que apresentou maiores valores de acúmulo de forragem, com exceção da estação verão 1 , fato que pode ser atribuído ao equilíbrio de luz, água e nutrientes. Com o excesso de sombra no espaçamento $3 \times 2 \mathrm{~m}$ houve efeito deletério no acúmulo de forragem.

Para acúmulo de forragem do capim-braquiária no espaçamento $6 \times 4 \mathrm{~m}$ nas estações verão 1 , primavera e verão 2 , houve efeito quadrático negativo $(\mathrm{P}<0,05)$ para as distâncias da linha de plantio do eucalipto $(0$, 33, 66 e 99,99\%), com valor máximo estimado em 3083 kg.ha- ${ }^{-1}, 2343 \mathrm{~kg} \cdot \mathrm{ha}^{-1}, 3783 \mathrm{~kg} \cdot \mathrm{ha}^{-1}$, correspondente as distâncias da linha de plantio do eucalipto de 55\%, $46 \%$ e $53 \%$, respectivamente (Figura 1 ).

O maior acúmulo de forragem foi nas distancias de $33,33 \%$ e $66,66 \%$ da linha do eucalipto e pode ser associado a uma suposta melhor qualidade do solo e a sombra fornecida favorecer positivamente alterações nos processos bioquímicos da planta forrageira.

No outono houve efeito linear positivo $(\mathrm{P}<0,05)$ para acúmulo de forragem no espaçamento $6 \times 4 \mathrm{~m}$ (Figura 2), com aumento de $25,10 \mathrm{~kg} \cdot \mathrm{ha}^{-1}$ a cada aumento de distância da linha de plantio do eucalipto.

Quanto mais distante da linha de plantio do eucalipto, aumentou-se o acúmulo de forragem, devido ao tamanho das copas do eucalipto estar maior no outono, fornecendo um maior sombreamento.

No espaçamento $10 \times 4 \mathrm{~m}$, houve efeito linear positivo $(\mathrm{P}<0,05)$ com aumento de 33,48 kg.ha' ${ }^{-1}$ e 11,46 kg.ha${ }^{1}$ a cada aumento de distância da linha de plantio do eucalipto nas estações verão 2 e outono (Figura 3 ).

Este resultado pode esta relacionado ao tamanho das copas das árvores, por estarem maiores durante as estações verão 2 e outono, promovendo maior sombreamento no capim-braquiária nas linhas mais próxima da linha de plantio do eucalipto.

Tabela 1 - Acúmulo de forragem (kg.ha- ${ }^{1}$ ) do capim-braquiária em sistema silvipastoril com Eucalyptus urophylla sob diferentes espaçamentos $(3 \times 2,6 \times 4$ e 10x4 m) e em monocultivo nas diferentes estações (verão 1, primavera, verão 2 e outono)

\begin{tabular}{lcccc}
\hline \multirow{2}{*}{ Estações } & \multicolumn{4}{c}{ Espaçamentos } \\
\cline { 2 - 4 } & monocultivo & $3 \times 2 \mathrm{~m}$ & $6 \times 4 \mathrm{~m}$ & $10 \times 4 \mathrm{~m}$ \\
\hline Verão 1 & $3.382^{\mathrm{aB}}$ & $2.644^{\mathrm{abAB}}$ & $2.408^{\mathrm{abA}}$ & $2.093^{\mathrm{bB}}$ \\
Primavera & $4.439^{\mathrm{aB}}$ & $1.784^{\mathrm{bB}}$ & $1.829^{\mathrm{bA}}$ & $2045^{\mathrm{bB}}$ \\
Verão 2 & $6.167^{\mathrm{aA}}$ & $3.139^{\mathrm{cA}}$ & $3.078^{\mathrm{cA}}$ & $4.327^{\mathrm{bA}}$ \\
Outono & $5.851^{\mathrm{aA}}$ & $1.570^{\mathrm{bB}}$ & $2.045^{\mathrm{bA}}$ & $2.324^{\mathrm{bB}}$ \\
\hline
\end{tabular}

Médias seguidas de letras iguais minúsculas na linha e maiúsculas na coluna não diferem entre si pela probabilidade da diferença ("DIFF"), a 5\% de probabilidade. EPM - Erro Padrão da Média. 
A taxa de acúmulo de forragem do capim-braquiária foi maior em todas as estações avaliadas no monocultivo (Tabela 2).
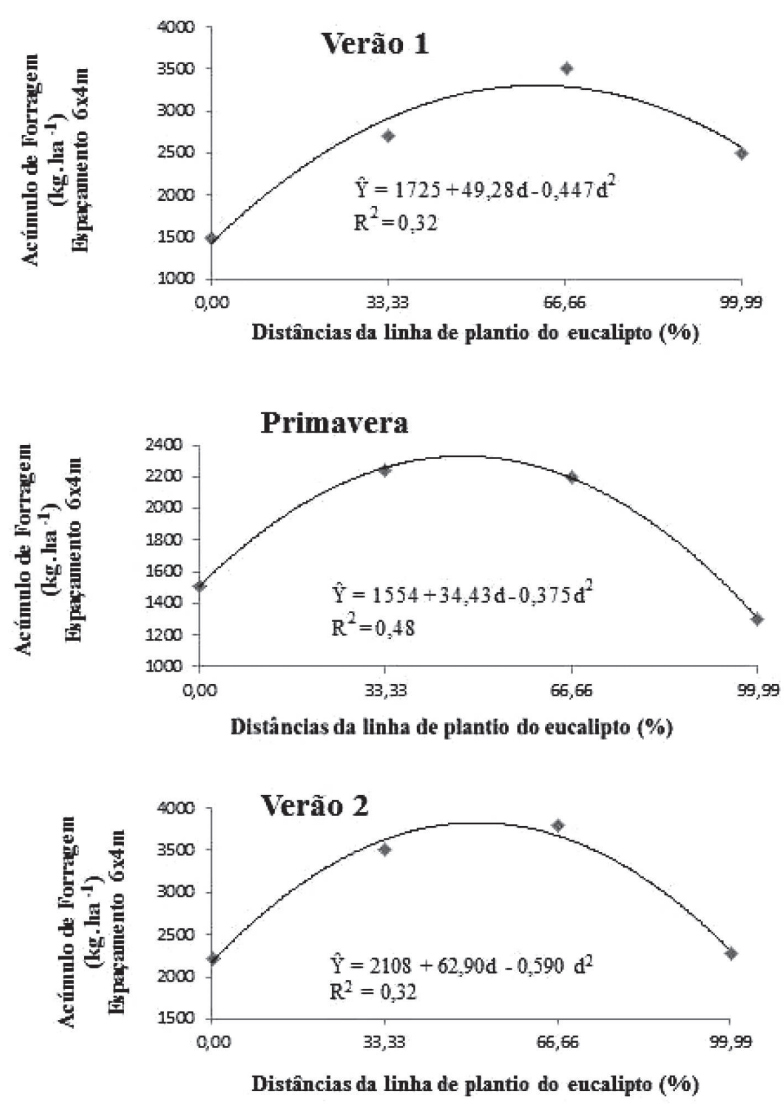

Figura 1 - Acúmulo de forragem do capim-braquiária no espaçamento 6x4 m nas linhas de distância de plantio do eucalipto $(0 ; 33,33 ; 66,66 ; 99,99 \%)$ nas estações verão 1 , primavera e verão 2 . $\mathrm{R}^{2}$ : coeficiente de determinação. d: distância.

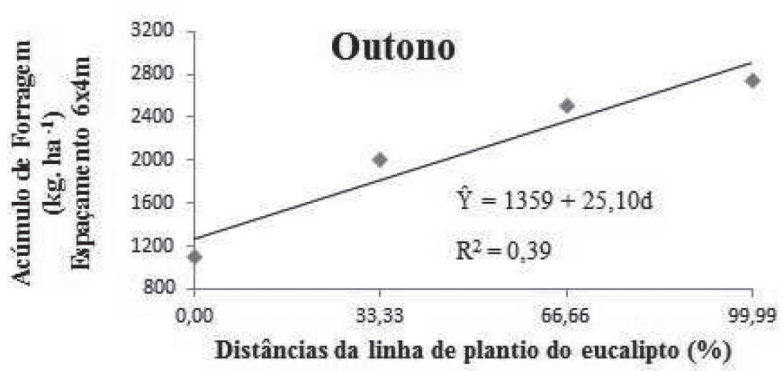

Figura 2 - Acúmulo de forragem do capim-braquiária nos espaçamentos $6 \times 4 \mathrm{~m}$ nas linhas de distancia do eucalipto $(0 ; 33,33 ; 66,66 ; 99,99 \%)$ na estação outono.
Foi verificado comportamento semelhante ao acúmulo de forragem para taxa de acúmulo de forragem. Acúmulo e taxa de acúmulo de forragem são influenciados pelos espaçamentos.

Houve efeito quadrático negativo $(\mathrm{P}<0,05)$ para taxa de acúmulo de forragem no espaçamento $6 \mathrm{x} 4 \mathrm{~m}$ nas estações verão 1 , primavera e verão 2 com valores máximos de 11,52; 45,12; 6,76 kg.ha-1 $\cdot$ dia $^{-1}$, correspondente a distância das linhas de plantio do eucalipto de 57, 53,5 e 46\%, respectivamente (Figura 4 ). O resultado verificado pode ser explicado pela menor competição de luz solar, água e nutrientes entre o eucalipto e o capim braquiária nas linhas 33,33\% e 66,66\% (Ribeiro, 2012).

$\mathrm{Na}$ estação outono houve efeito linear positivo $(\mathrm{P}<0,05)$ para taxa de acúmulo de forragem no espaçamento $6 \times 4 \mathrm{~m}$, com aumento de $0,32 \mathrm{~kg} \cdot \mathrm{ha}^{-1} \cdot \mathrm{dia}^{-1}$ com aumento de distância da linha de plantio do eucalipto (Figura 5).

Quanto mais distante da linha de plantio do eucalipto, na estação outono, maiores foram os valores de taxa de acúmulo de forragem, pois ocorreu um sombreamento mais intenso na linha do eucalipto, e a quantidade e a qualidade de luz que chegava ao dossel forrageiro foi reduzida (Paciullo et al., 2008).
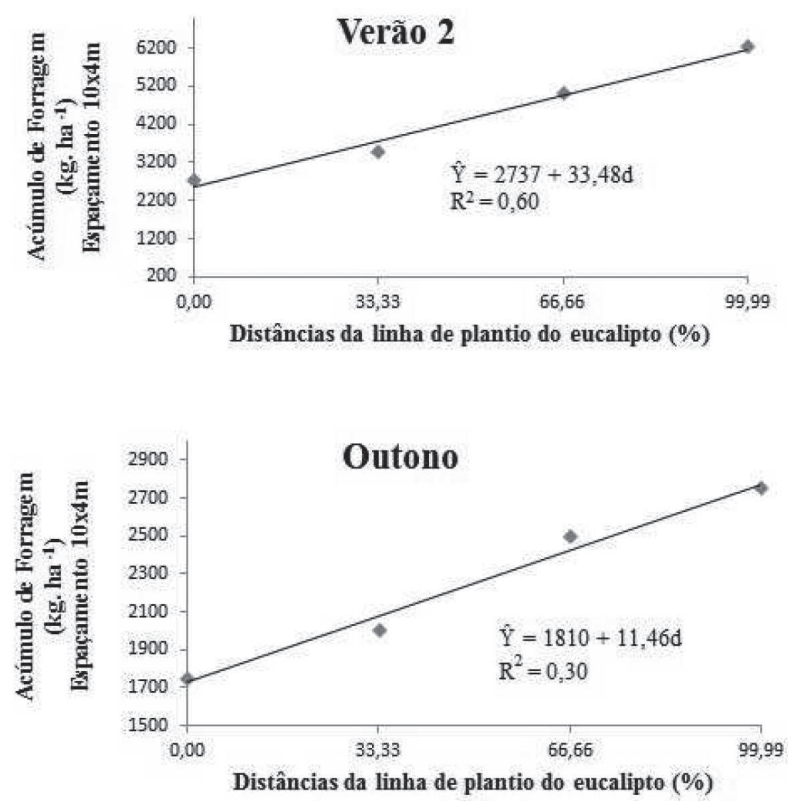

Figura 3 - Acúmulo de forragem do capim-braquiária nos espaçamentos 10x4 m nas linhas de distância do eucalipto $(0 ; 33,33 ; 66,66 ; 99,99 \%)$ nas estações verão 2 e outono. 
Tabela 2. Taxa de acúmulo de forragem (kg.ha-1 $\cdot \mathrm{dia}^{-1}$ de MS) do capim-braquiária em sistema silvipastoril com Eucalyptus urophylla sob diferentes espaçamentos $(3 \times 2,6 \times 4$ e 10x4 m) e em monocultivo nas diferentes estações (verão 1 , primavera, verão 2 e outono)

\begin{tabular}{|c|c|c|c|c|c|}
\hline \multirow{2}{*}{ Estações } & \multicolumn{4}{|c|}{ Espaçamentos } & \multirow{2}{*}{ EPM } \\
\hline & monocultivo & $3 \times 2 \mathrm{~m}$ & $6 \times 4 \mathrm{~m}$ & $10 \times 4 \mathrm{~m}$ & \\
\hline Verão 1 & $12,47^{\mathrm{aC}}$ & $9,77^{\mathrm{abCB}}$ & $8,87^{\mathrm{abB}}$ & $7,72^{\mathrm{bC}}$ & 1,68 \\
\hline Primavera & $19,22^{\mathrm{aB}}$ & $7,72^{\mathrm{bC}}$ & $7,92^{\mathrm{bB}}$ & $8,85^{\mathrm{bC}}$ & 1,38 \\
\hline Verão 2 & $73,42^{\mathrm{aA}}$ & $37,40^{\mathrm{bA}}$ & $36,65^{\mathrm{bA}}$ & $51,50^{\mathrm{bA}}$ & 5,22 \\
\hline Outono & $76,37^{\mathrm{aA}}$ & $20,40^{\mathrm{bAB}}$ & $26,50^{\mathrm{bA}}$ & $30,50^{\mathrm{bB}}$ & 5,83 \\
\hline
\end{tabular}

Médias seguidas de letras iguais minúsculas na linha e maiúsculas na coluna não diferem entre si pela probabilidade da diferença ("DIFF"), a 5\% de probabilidade. EPM - Erro Padrão da Média.
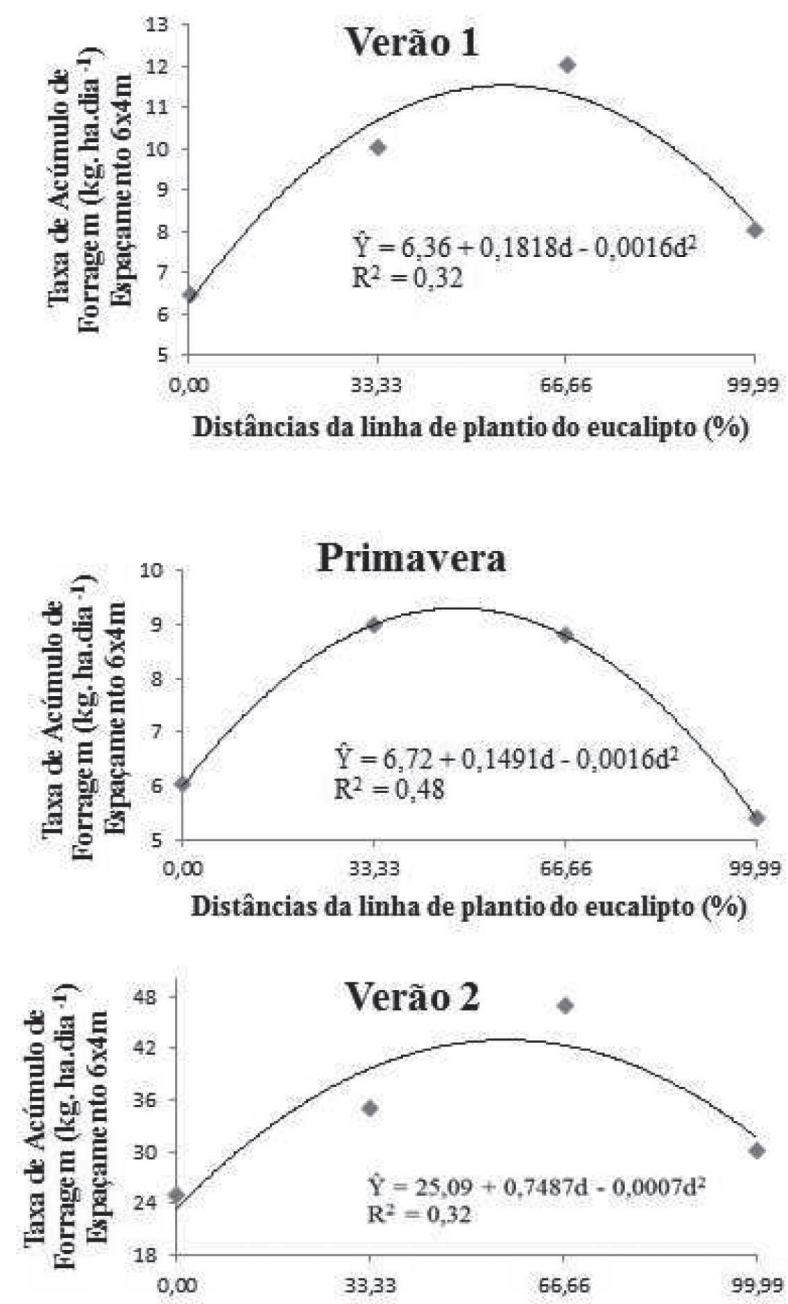

Figura 4 - Taxa de acúmulo de forragem do capim-braquiária no espaçamento $6 \times 4 \mathrm{~m}$ nas linhas de distância do eucalipto $(0 ; 33,33 ; 66,66 ; 99,99 \%)$ nas estações verão 1 , primavera e varão $2 . R^{2}$ : coeficiente de determinação. d: distância.

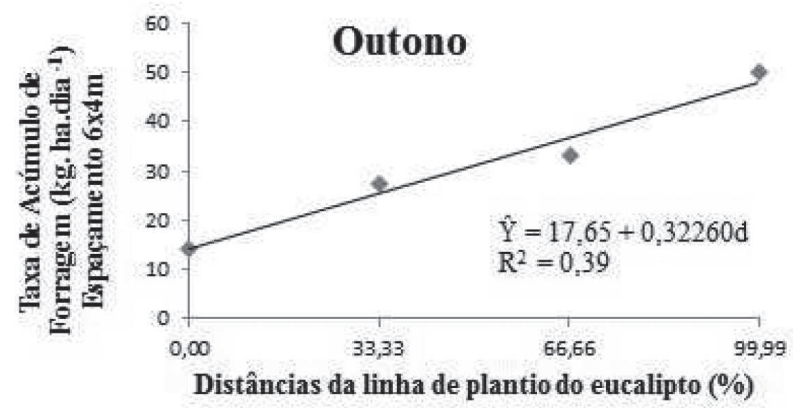

Figura 5 - Taxa de acúmulo de forragem do capim-braquiária no espaçamento $6 \times 4 \mathrm{~m}$ nas linhas de distância do eucalipto $(0 ; 33,33 ; 66,66 ; 99,99 \%)$ na estação outono. $\mathrm{R}^{2}$ : coeficiente de determinação. d: distância.

Houve efeito linear $(\mathrm{P}<0,05)$ positivo para o espaçamento $10 \times 4 \mathrm{~m}$ nas estações verão 2 e outono. $\mathrm{O}$ aumento da taxa de acúmulo de forragem foi de 0,39 e $0,14 \mathrm{~kg} \cdot \mathrm{ha}^{-1} \cdot \mathrm{dia}^{-1}$ a cada aumento da distância da linha de plantio do eucalipto (Figura 6). Fato provavelmente ocorrido com a entrada de radiação solar em melhor qualidade e quantidade, seguida da menor competição por outros recursos, como água e nutrientes.

Dentre os sistemas sombreados o espaçamento $10 \times 4 \mathrm{~m}$ apresentou maior valor em altura e o menor valor encontrado foi no espaçamento $3 \times 2 \mathrm{~m}$ (Tabela 3 ).

Em Panicum maximum cv Tanganica submetido ao sombreamento foi verificado que com aumento do sombreamento os valores de altura decresceram, e poderia ser justificado pelo sombreamento ter sido muito intenso e não ter permitindo a entrada suficiente de radiação solar (Silvestre, 2011). Os menores valores foram observados no espaçamento $3 \times 2 \mathrm{~m}$, com exceção da estação verão 2 (Tabela 4). 

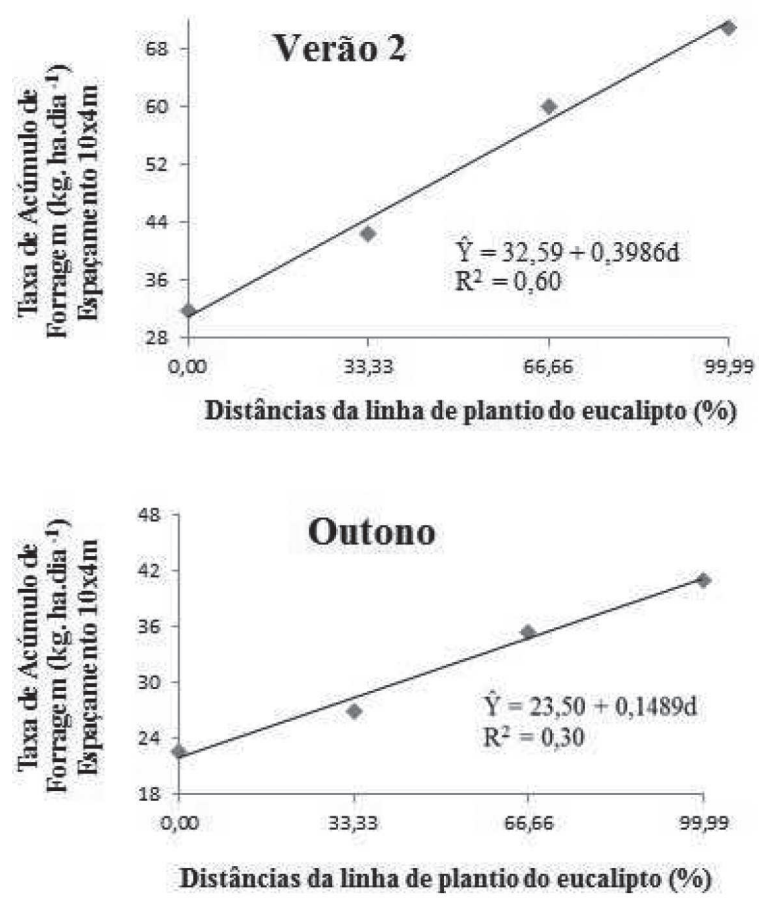

Figura 6 - Taxa de acúmulo de forragem do capim-braquiária no espaçamento $10 \times 4 \mathrm{~m}$ nas distâncias da linha de plantio do eucalipto $(0 ; 33,33 ; 66,66 ; 99,99 \%)$ nas estações verão 2 e outono. $R^{2}$ : coeficiente de determinação. d: distância.
Em ambientes sombreados, a evapotranspiração é diminuída e a disponibilidade de água nas plantas forrageiras é maior (Carvalho, 1995). As gramíneas que são submetidas ao sombreamento, apresentam menor teor de matéria seca (PERI et al., 2007), e consequentemente mais água nos tecidos das plantas (Kyniamario et al., 1995). Nas estações primavera e verão 2 , o resultado pode ter sido ocasionado pelo baixo índice pluviométrico no período de avaliação, aumentando a competição por água entre a gramínea e as árvores de eucalipto.

Os valores de proteína bruta não foram influenciados significativamente pelo sombreamento, com exceção do espaçamento $6 \times 4 \mathrm{~m}$ no outono (Tabela 5).

Devido à umidade mais alta do ambiente e temperaturas mais amenas do solo, a mineralização do nitrogênio foi favorecida (Wilson, 1996) em conjunto com a entrada de luz suficiente para alterar os processos fisiológicos e favorecer um incremento de nitrogênio.

O teor de matéria mineral do capim-braquiária no verão 1 , nos ambientes sombreados, teve seu menor valor no espaçamento $6 \times 4 \mathrm{~m}$. No verão 2 e outono, o maior valor foi verificado no espaçamento $3 \times 2$ e $10 \times 4$ $\mathrm{m}$, respectivamente (Tabela 6).

Em estudo com capim braquiária, Lima et al. (2012) verificaram que em espaçamentos mais adensados, houve

Tabela 3 - Altura (cm) do capim-braquiária em sistema silvipastoril com Eucalyptus urophylla sob diferentes espaçamentos $(3 \times 2,6 \times 4$ e $10 \times 4 \mathrm{~m})$ e em monocultivo nas diferentes estações (verão 1 , primavera, verão 2 e outono)

\begin{tabular}{lccccc}
\hline \multirow{2}{*}{ Estações } & \multicolumn{4}{c}{ Espaçamentos } & \multicolumn{1}{c}{ EPM } \\
\cline { 2 - 5 } & monocultivo & $3 \times 2 \mathrm{~m}$ & $6 \times 4 \mathrm{~m}$ & $33^{\mathrm{aB}}$ & 2,12 \\
Verão 1 & $33^{\mathrm{aB}}$ & $25^{\mathrm{bA}}$ & $32^{\mathrm{aA}}$ & $29^{\mathrm{BB}}$ & 1,60 \\
Primavera & $35^{\mathrm{aB}}$ & $21^{\mathrm{cAB}}$ & $24^{\mathrm{cB}}$ & $31^{\mathrm{aA}}$ & 3,04 \\
Verão 2 & $42^{\mathrm{aA}}$ & $27^{\mathrm{bA}}$ & $23^{\mathrm{cB}}$ & $31^{\mathrm{bB}}$ \\
Outono & $45^{\mathrm{aA}}$ & $17^{\mathrm{cB}}$ & 2,47 \\
\hline
\end{tabular}

Médias seguidas de letras iguais minúsculas na linha e maiúsculas na coluna não diferem entre si pela probabilidade da diferença ("DIFF"), a 5\% de probabilidade. EPM - Erro Padrão da Média.

Tabela 4 - Matéria seca (\%) da capim-braquiária em sistema silvipastoril com Eucalyptus urophylla sob diferentes espaçamentos (3x2, 6x4 e 10x4 m) e em monocultivo nas diferentes estações (verão 1, primavera, verão 2 e outono)

\begin{tabular}{lcccc}
\hline \multirow{2}{*}{ Estações } & \multicolumn{4}{c}{ Espaçamentos } \\
\cline { 2 - 5 } & monocultivo & $3 \times 2 \mathrm{~m}$ & $6 \times 4 \mathrm{~m}$ & $10 \times 4 \mathrm{~m}$ \\
\hline Verão 1 & $25,5^{\mathrm{aB}}$ & $21,3^{\mathrm{bB}}$ & $21,8^{\mathrm{bC}}$ & $21,5^{\mathrm{bC}}$ \\
Primavera & $27,5^{\mathrm{aB}}$ & $24,0^{\mathrm{aB}}$ & $27,0^{\mathrm{aB}}$ & $26,3^{\mathrm{aB}}$ \\
Verão 2 & $39,1^{\mathrm{aA}}$ & $44,0^{\mathrm{aA}}$ & $35,8^{\mathrm{aA}}$ & $39,5^{\mathrm{aA}}$ \\
Outono & $49,8^{\mathrm{aA}}$ & $16,6^{\mathrm{cB}}$ & $36,4^{\mathrm{bA}}$ & $36,4^{\mathrm{bA}}$ \\
\hline
\end{tabular}

Médias seguidas de letras iguais minúsculas na linha e maiúsculas na coluna não diferem entre si pela probabilidade da diferença ("DIFF"), a $5 \%$ de probabilidade. EPM - Erro Padrão da Média. 
aumento no percentual de matéria mineral, o que corrobora com este estudo, nas estações primavera e verão 2 . No outono, o resultado pode ser explicado devido ao aumento das copas das árvores proporcionarem uma sombra mais intensa, causando efeito deletério na absorção de nutrientes nos espaçamentos 3x2 e 6x4 m, uma vez que o maior valor encontrado foi no espaçamento $10 \mathrm{x} 4 \mathrm{~m}$.

O teor de fibra em detergente neutro não apresentou interações entre as estações e os tratamentos avaliados. O maior valor foi encontrado na estação verão 2, atribuído provavelmente aos maiores valores verificados de altura nesta estação em todos os espaçamentos e no monocultivo (Figura 7a). E o espaçamento $3 \times 2 \mathrm{~m}$ apresentou menor valor de fibra em detergente neutro (Figura 7b), o que pode ser justificado pela menor espessura de tecido esclerenquimático em plantas forrageiras submetidas ao sombreamento intenso (Paciullo et al., 2007), associado a menores valores de altura.

Houve efeito linear positivo $(\mathrm{P}<0,05)$ para altura do eucalipto com aumento de

0,4 m/mês pós-plantio das árvores (Figura 8).

Os maiores valores foram verificados nos espaçamentos 6x4 e 10x4 m (Figura 9).

Este resultado é comumente encontrado na literatura (Macedo et al., 2013), pois há uma supressão no

Tabela 5 - Proteína Bruta (\%) do capim-braquiária em sistema silvipastoril com Eucalyptus urophylla sob diferentes espaçamentos $(3 \times 2,6 \times 4$ e $10 \times 4 \mathrm{~m})$ e em monocultivo nas diferentes estações (verão 1 , primavera, verão 2 e outono)

\begin{tabular}{|c|c|c|c|c|c|}
\hline \multirow{2}{*}{ Estações } & \multicolumn{4}{|c|}{ Espaçamentos } & \multirow{2}{*}{ EPM } \\
\hline & monocultivo & $3 \times 2 \mathrm{~m}$ & $6 \times 4 \mathrm{~m}$ & $10 \times 4 \mathrm{~m}$ & \\
\hline Verão 1 & $9,9^{\mathrm{aA}}$ & $8,0^{\mathrm{aA}}$ & $9,1^{\mathrm{aA}}$ & $8,2^{\mathrm{aA}}$ & 1,2 \\
\hline Primavera & $8,0^{\mathrm{aA}}$ & $7,9^{\mathrm{aA}}$ & $7,4^{\mathrm{aA}}$ & $8,5^{\mathrm{aA}}$ & 1,7 \\
\hline Verão 2 & $5,8^{\mathrm{bC}}$ & $7,4^{\mathrm{abA}}$ & $8,6^{\mathrm{aA}}$ & $7,9^{\mathrm{abA}}$ & 3,1 \\
\hline Outono & $4,2^{\mathrm{bB}}$ & $5,2^{\mathrm{bB}}$ & $9,0^{\mathrm{aA}}$ & $5,7^{\mathrm{bB}}$ & 3,9 \\
\hline
\end{tabular}

Médias seguidas de letras iguais minúsculas na linha e maiúsculas na coluna não diferem entre si pela probabilidade da diferença ("DIFF"), a 5\% de probabilidade. EPM - Erro Padrão da Média.

Tabela 6 - Matéria mineral (\%) do capim-braquiária em sistema silvipastoril com Eucalyptus urophylla sob diferentes espaçamentos ( $3 \times 2,6 \times 4$ e 10x4 m) e em monocultivo nas diferentes estações (verão 1, primavera, verão 2 e outono)

\begin{tabular}{lcccc}
\hline \multirow{2}{*}{ Estações } & \multicolumn{4}{c}{ Espaçamentos } \\
\cline { 2 - 5 } & monocultivo & $3 \times 2 \mathrm{~m}$ & $6 \times 4 \mathrm{~m}$ & $10 \times 4 \mathrm{~m}$ \\
\hline Verão 1 & $7,4^{\mathrm{aA}}$ & $6,5^{\mathrm{abAB}}$ & $5,0^{\mathrm{bB}}$ & $6,2^{\mathrm{abAB}}$ \\
Primavera & $6,8^{\mathrm{aA}}$ & $7,1^{\mathrm{aA}}$ & $6,4^{\mathrm{aAB}}$ & $6,7^{\mathrm{aA}}$ \\
Verão 2 & $6,1^{\mathrm{abA}}$ & $7,3^{\mathrm{aA}}$ & $7,1^{\mathrm{aA}}$ & $4,8^{\mathrm{bB}}$ \\
Outono & $6,3^{\mathrm{abA}}$ & $4,7^{\mathrm{bB}}$ & $5,9^{\mathrm{bAB}}$ & $7,6^{\mathrm{aA}}$ \\
\hline
\end{tabular}

Médias seguidas de letras iguais minúsculas na linha e maiúsculas na coluna não diferem entre si pela probabilidade da diferença (“DIFF”), a 5\% de probabilidade. EPM - Erro Padrão da Média.

a

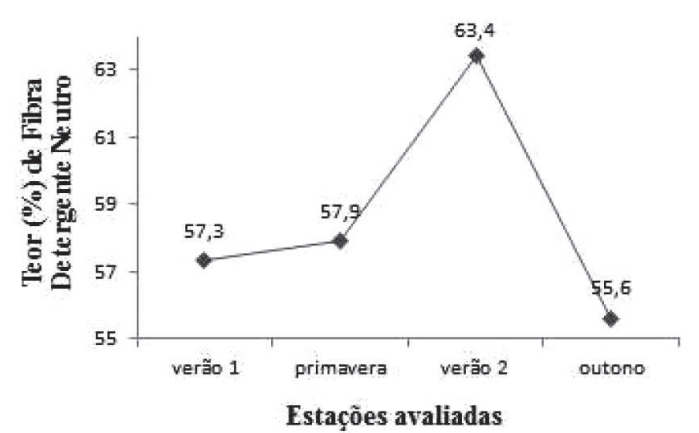

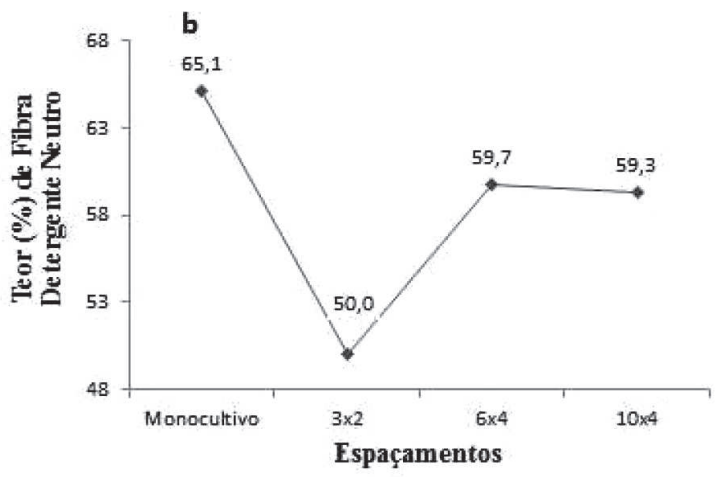

Figura 7 - a) Teor de fibra em detergente neutro no verão 1, primavera, verão 2 e outono. 7 b) Teor de fibra em detergente neutro no monocultivo e nos espaçamentos $3 \times 2,6 \times 4$ e $10 \times 4 \mathrm{~m}$. 
crescimento em diâmetro devido a uma maior competição entre plantas nos espaçamentos adensados.

A relação altura:diâmetro à altura do peito, apresentou maior valor no espaçamento $3 \times 2 \mathrm{~m}$ (Figura 10).

A idade de pós-plantio das árvores interfere na relação altura:DAP, pois com o passar do tempo as variáveis altura e DAP sofrem alterações. Porém ao atingir o clímax de crescimento, estas alterações tendem a reduzir (Scolforo, 1997). Neste sentido, quando a competição entre árvores for alta, a relação altura: DAP

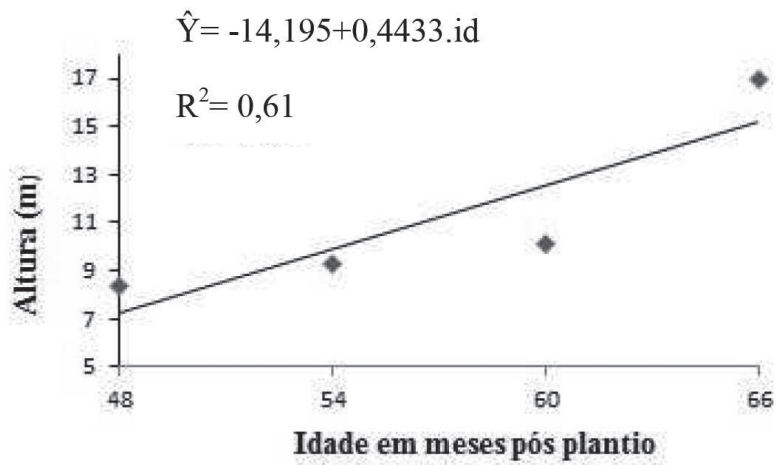

Figura 8 - Altura (m) do Eucalyptus urophylla aos 48, 54, 60 e 66 meses pós-plantio. $\mathrm{Id}=$ idade. $\mathrm{R}^{2}=$ coeficiente de determinação.

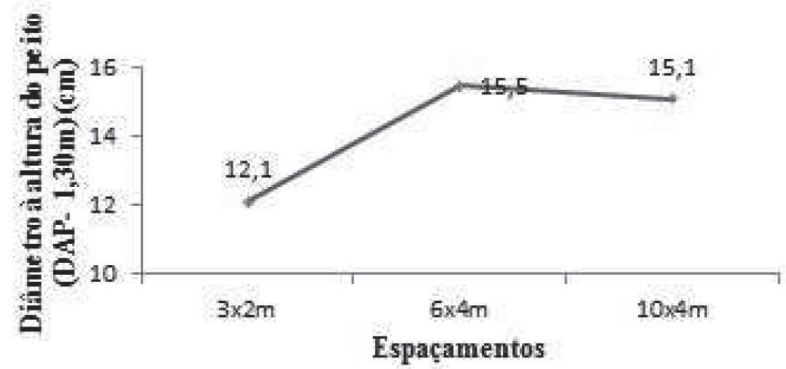

Figura 9 - Diâmetro à altura do peito $(\mathrm{cm})$ do Eucalyptus urophylla em diferentes espaçamentos $3 \times 2,6 \times 4$ e 10x4 m. Probabilidade 5\%.

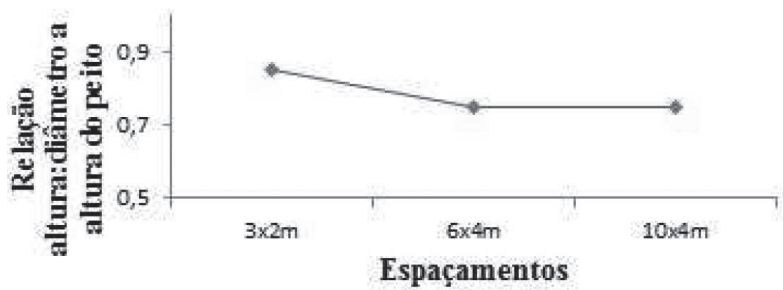

Figura 10 - Relação altura:diâmetro à altura do peito do Eucalyptus urophylla nos espaçamentos $3 \times 2,6 \times 4$ e $10 \times 4 \mathrm{~m}$. Probabilidade 5\%. será maior que a competição mais moderada (Caldeira et al., 2003). Fato observado no espaçamento $3 \times 2 \mathrm{~m}$.

Houve efeito quadrático positivo $(\mathrm{P}<0,05)$ para diâmetro de copa nos espaçamentos $3 \times 2,6 \times 4$ e 10x4 m, com valores mínimos estimados em 0,$2 ; 3,6 ; 4,0$ metros, correspondentes a 59,56 e 56 meses de idade pós-plantio, respectivamente (Figura 11).
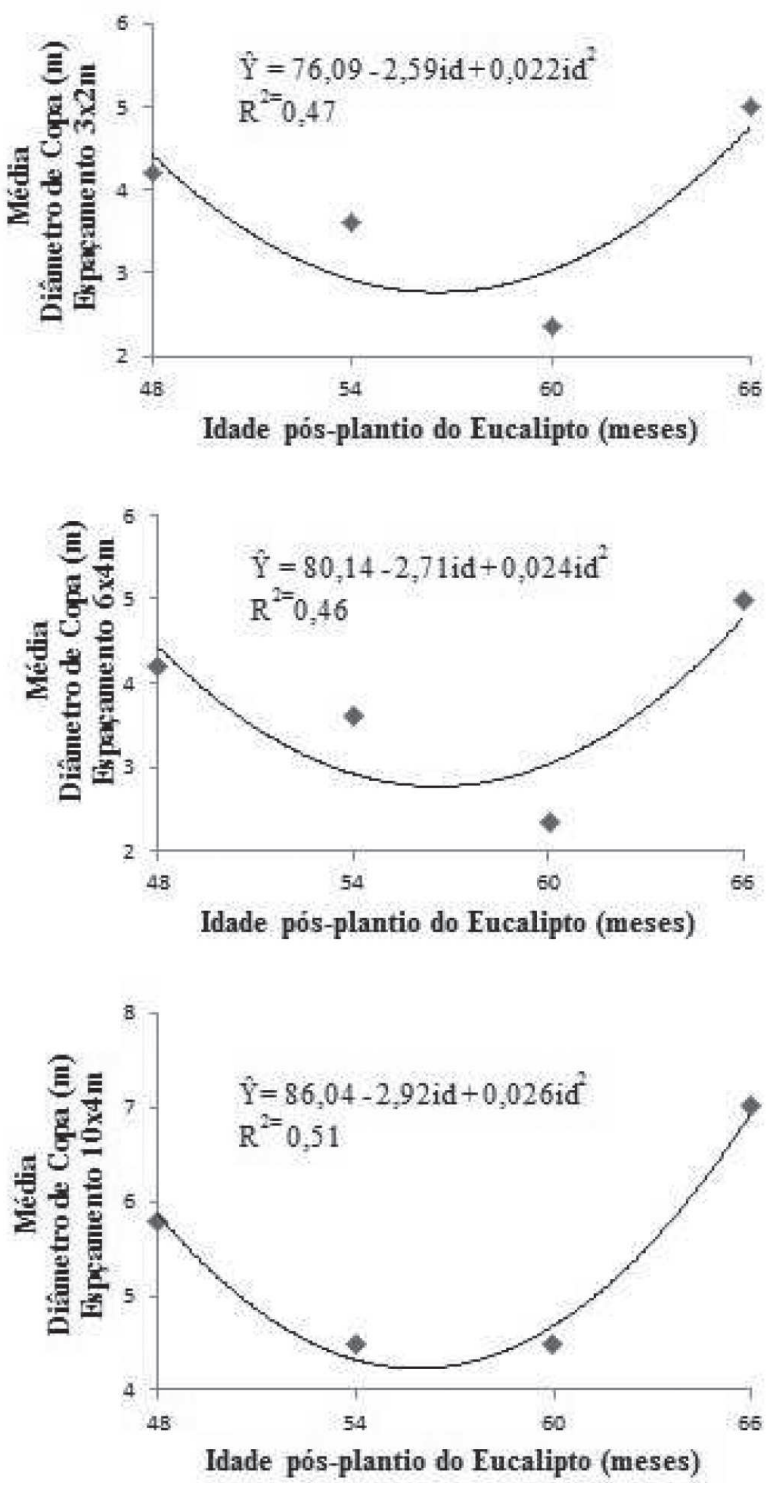

Figura 11 - Diâmetro de copa do Eucalyptus urophylla nos espaçamentos $3 \times 2,6 \times 4$ e $10 \times 4 \mathrm{~m}$ aos 48,54 , 60 e 66 meses pós-plantio em um sistema silvipastoril. $\mathrm{Id}=$ idade. $\mathrm{R}^{2}=$ coeficiente de determinação. 
Este resultado ocorreu provavelmente devido a desrama natural, ocorrida aos 54 e 60 meses pós plantio, com a falta do trato cultural de desrama, as copas cresceram continuadamente e contribuíram para queda de produção de capim-braquiária nos sistemas silvipastoris.

Houve efeito linear positivo para volume/planta nos espaçamentos $3 \times 2,6 \times 4$ e $10 \times 4 \mathrm{~m}$, com aumento de 0,$0065 ; 0,0098 ; 0,0076 \mathrm{~m}^{3} /$ mês pós-plantio do eucalipto (Tabela 7).

O volume por planta foi maior aos 66 meses de idade pós-plantio no espaçamento $6 \times 4 \mathrm{~m}$, seguido do espaçamento $10 \times 4 \mathrm{~m}$, pois esta variável está diretamente relacionada ao valor de altura e diâmetro a altura do peito, neste estudo os maiores valores de DAP ocorreram nos espaçamentos 6x4 e 10x4 m, respectivamente. $\mathrm{O}$ menor resultado foi encontrado no espaçamento $3 \times 2 \mathrm{~m}$ devido a uma maior competição entre as plantas neste espaçamento, limitando o crescimento individual.

Houve efeito linear positivo para volume/ha nos espaçamentos $3 \times 2 ; 6 \times 4$ e $10 \times 4 \mathrm{~m}$, com aumento de 10,$83 ; 4,05 ; 1,89 \mathrm{~m}^{3} /$ mês pós-plantio do eucalipto (Tabela 8).

$\mathrm{O}$ volume/ha foi maior nos espaçamentos mais adensados, resultado já observado por diversos autores, que afirmaram que a variável volume/ha está intimamente relacionada ao número de árvores por hectare (Macedo et al., 2010). Neste experimento, até 5,5 anos, o espaçamento $3 \times 2 \mathrm{~m}$ é o mais produtivo.

Houve efeito linear positivo $(\mathrm{P}<0,05)$ para incremento médio anual nos espaçamentos $3 \times 2 ; 6 \times 4$ e $10 \times 4 \mathrm{~m}$, com aumento de 0,$03 ; 0,62$ e $0,28 \mathrm{~m}^{3}$ por mês pós-plantio do eucalipto (Figura 12).

\section{CONCLUSÕES}

As características produtivas do capim braquiária foram influenciadas pelos espaçamentos de plantio do eucalipto.

Quanto às características bromatológicas, o sistema silvipastoril favoreceu a percentual de água nas plantas forrageiras, principalmente no outono.

O espaçamento $3 \times 2 \mathrm{~m}$ apresentou maior estabilidade aos 5,5 anos.

A produção por hectare foi dependente do número de indivíduos por hectare, sendo o espaçamento $3 \times 2$ $\mathrm{m}$ mais produtivo até os 5,5 anos de avaliação.

Para utilização de sistemas silvipastoris até os 5,5 anos, visando produção e qualidade de pasto e produção de madeira, o espaçamento mais indicado foi o $6 \times 4 \mathrm{~m}$.

Tabela 8 - Volume/ha do Eucalyptus urophylla nos espaçamentos (esp.) 3x2, 6x4 e 10x4 m nas idades de 48, 54, 60 e 66 meses pós-plantio do eucalipto.

\begin{tabular}{|c|c|c|c|c|c|c|c|}
\hline \multirow{2}{*}{ Esp. } & \multicolumn{4}{|c|}{ Idade em meses pós-plantio } & \multirow{2}{*}{ EPM } & \multirow{2}{*}{ Equação } & \multirow{2}{*}{$\mathrm{R}^{2}$} \\
\hline & 48 & 54 & 60 & 66 & & & \\
\hline $3 \times 2$ & $45,35^{\mathrm{A}}$ & $60,17^{\mathrm{A}}$ & $77,75^{\mathrm{A}}$ & $256,13^{\mathrm{A}}$ & & $\hat{\mathrm{Y}}=-507,56+10,832 . \mathrm{id}$ & 0,47 \\
\hline $6 \times 4$ & $23,50^{\mathrm{B}}$ & $24,87^{\text {B }}$ & $29,42^{\mathrm{B}}$ & $103,10^{\mathrm{B}}$ & 7,981 & $\hat{Y}=-185,96+4,0558 . \mathrm{id}$ & 0,62 \\
\hline $10 \times 4$ & $13,40^{\mathrm{B}}$ & $15,95^{\mathrm{B}}$ & $20,02^{\mathrm{B}}$ & $49,92^{\mathrm{B}}$ & & $\hat{\mathrm{Y}}=-83,178+1,895 . \mathrm{id}$ & 0,44 \\
\hline
\end{tabular}

Médias seguidas de letras iguais maiúsculas nas colunas não diferem entre si pela probabilidade da diferença ("DIFF"), a $5 \%$ de probabilidade. $\mathrm{Id}=$ idade. Esp. = espaçamentos. $\mathrm{R}^{2}=$ coeficiente de determinação. $\mathrm{EPM}=$ erro padrão da média.

Tabela 7 - Volume/planta do Eucalyptus urophylla nos espaçamentos (esp.) 3x2, 6x4 e 10x4 m nas idades de 48, 54, 60 e 66 meses pós-plantio do eucalipto

\begin{tabular}{lccccccc}
\hline \multirow{2}{*}{ Esp. } & \multicolumn{3}{c}{ Idade em meses pós-plantio } & & \multirow{2}{*}{ EPM } & & Equação \\
\cline { 2 - 4 } & 48 & 54 & 60 & 66 & & $R^{2}$ \\
\hline $3 \times 2$ & $0,027^{\mathrm{B}}$ & $0,036^{\mathrm{B}}$ & $0,046^{\mathrm{A}}$ & $0,153^{\mathrm{B}}$ & & $\hat{\mathrm{Y}}=-0,3038+0,0065 . \mathrm{id}$ \\
$6 \times 4$ & $0,056^{\mathrm{A}}$ & $0,059^{\mathrm{A}}$ & $0,070^{\mathrm{A}}$ & $0,247^{\mathrm{A}}$ & & 0,007 & $\hat{\mathrm{Y}}=-0,4473+0,0098 . \mathrm{id}$ \\
$10 \times 4$ & $0,053^{\mathrm{A}}$ & $0,063^{\mathrm{A}}$ & $0,080^{\mathrm{A}}$ & $0,199^{\mathrm{AB}}$ & & $\hat{\mathrm{Y}}=-0,3337+0,0076 . \mathrm{id}$ & 0,58 \\
\hline
\end{tabular}

Médias seguidas de letras iguais maiúsculas nas colunas não diferem entre si pela probabilidade da diferença ("DIFF"), a 5\% de probabilidade. $\mathrm{Id}=$ idade. Esp. = espaçamentos. $\mathrm{R}^{2}=$ coeficiente de determinação. $\mathrm{EPM}=$ erro padrão da média. 

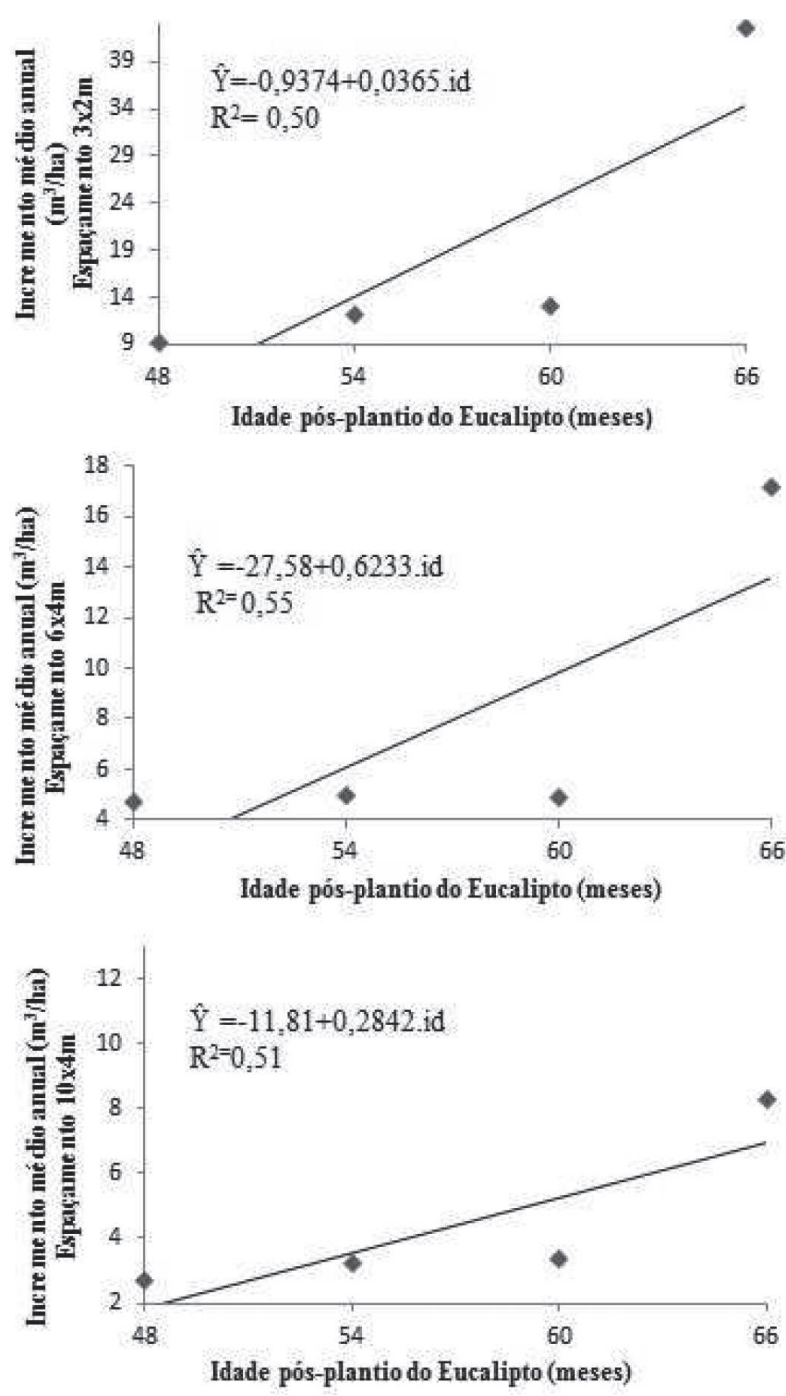

Figura 12 - Incremento médio anual ( $\left.\mathrm{m}^{3} / \mathrm{ha}\right)$ do Eucalyptus urophylla nos espaçamentos $3 \times 2,6 \times 4$ e $10 \times 4$ $\mathrm{m}$ aos 48, 54, 60 e 66 meses pós-plantio em um sistema silvipastoril. $\mathrm{Id}=$ idade $\mathrm{R}^{2}=$ coeficiente de determinação.

\section{LITERATURA CITADA}

CALDEIRA, M.V.W.; SCHUMACHER, M.V.; SCHEEREN, L.W.; WATZLAWICK, L.F. Relação hipsométrica para Araucaria angustifólia (Bert.) O. Ktze na região oeste do estado do Paraná. Revista Acadêmica: ciências agrárias e ambientais, Curitiba, v.1, n.2, p.79-88, 2003.
CANTARUTTI, R.B.; MARTINS, C.E.; CARVALHO, M.M. et al. Pastagens. In: RIBEIRO, A.C.; GUIMARÃES, P.T.G; ALVAREZ, V.H. (Eds.)

Recomendações para o uso de corretivos e fertilizantes em Minas Gerais. 5a. aproximação. Viçosa, MG: Comissão de Fertilidade do Solo do Estado de Minas Gerais, 1999. p.25-32.

CARVALHO, M.M.; FREITAS, V.P.; ANDRADE, A.C. Crescimento inicial de cinco gramíneas tropicais em um subbosque de angico-vermelho (Anadenanthera macrocarpa Benth.). Pasturas Tropicales, Colombia, v.17, p.24-30, 1995.

DA SILVA, S.C.; CUNHA, W.F. Métodos indiretos para estimar a massa de forragem em pastos de Cynodon spp. Pesquisa Agropecuária Brasileira, Brasília, v.38, p.981-989, 2003.

INMET - Instituto Nacional de Metereologia. Base de dados climáticos. Disponível em: <http://www.inmet.gov.br/> (Acessado em 4 de junho de 2014).

INSTITUTO BRASILEIRO DE GEOGRAFIA E ESTATÍSTICA - IBGE. Pesquisa pecuária municipal. Disponível em: http:<www. ibge .gov.br> (Acessado em: 20/11/2013. 2006).

KINYAMARIO, J.I.; TRILICA, M.J.; NJOKA, T.J. Influence of tree shade on plant water status, gas exchange and water use efficiency os Pannicum maximum Jacq. and Themeda triandra Forsk. in a Kenia savana. African Journal Ecology, v.33, p.114-123, 1995.

LIMA, M.A.; RIBEIRO, E.T.; AZEVEDO, F.H.V.; GOMES, R.S.; ARAÚJO, R.P.; SOARES, F.A.; PÁDUA, F.T.; ALMEIDA, J.C.C. Composição bromatológica da Brachiaria decumbens em sistema silvipastoril. In CONGRESSO BRASILEIRO EM ZOOTECNIA, Cuiabá, MT, 2012 /CD-ROM.

MACEDO, R.L.G.; VALE, A.B.; VENTURIN, N. Eucalipto em sistemas agroflorestais. Lavras: UFLA, 2010. 331p.

ONU, População mundial deve atingir 9,6 bilhões em 2050, diz novo relatório da ONU. Disponível em: http://www.onu.org.br/populacao-mundialdeve-atingir-96-bilhoes-em-2050-diz-novo-relatorioda-onu/> (Acessado em 9 de abril de 2014). 
PACIULLO, D.S.C.; CARVALHO, C.A.B.; AROEIRA, L.J.M.; MORENZ, M.J.F.; LOPES, F.C.F.; ROSSIELLO, R.O.P. Morfofisiologia e valor nutritivo do capim-braquiária sob sombreamento natural e a sol pleno. Pesquisa

Agropecuária Brasileira, Brasília, v.42, p.573-579, 2007.

PACIULLO, D.S.C.; CAMPOS, N.R.; GOMIDE, C.A.M.; CASTRO, C.R.T.; TAVELA, R.C.; ROSSIELLO, R.O.P. Crescimento de capimbraquiária influenciado pelo grau de sombreamento e pela estação do ano. Pesquisa Agropecuária Brasileira, Brasília, v.43, n.7, p.917-923, 2008.

PERI, P.L.; LUCAS, R.J.; MOOT, D.J. Dry matter production morphology and nutritive value of Dactylis glomerata growing under different light regimes. Agrofloresty Systems, v.70, p.63-70, 2007.

RIBEIRO, E.T. Características produtivas e qualitativas de sistemas silvipastoris na região dos Campos das Vertentes, MG. Dissertação (Mestrado em Zootecnia). Seropédica, RJ: UFRRJ, 2012. 71p.
SCOLFORO, J.R.S. Biometria Florestal 2, Técnicas de regressão aplicada para estimar: volume, biomassa, relação hipsométrica e múltiplos produtos de madeira. Lavras, UFLA/FAEPE/DCF, 1997. 292p.

SILVA, D.J.; QUEIROZ, A.C. Análises de alimentos: métodos químicos e biológicos. 3.ed. Viçosa: UFV, 2002. 235p.

SILVESTRE, M.F. Morfogênese e perfilhamento de dosséis de Panicum maximum cv. Tanganica submetidos ao sombreamento. Monografia. (Engenheiro Agrônomo). Seropédica, RJ: UFRRJ, 2011.28p.

WILSON, J.R. Shade-stimulated growth and nitrogen uptake by pastures grasses in a subtropical environment. Australian Journal of Agricultural Research, v.47, p.10751093, 1996.

WOLFINGER, R. Covariance structure selection in general mixed models. Communications in Statistics - Simulation, v.22, n.4, p.10791106, 1993.

Recebido para publicação em 10/03/2015 e aprovado em 30/07/2015. 